\title{
Family Caregivers' Experiences With Telehealth During COVID-19: Insights From Michigan
}

Minaksbi Raj, PbD, MPH

Bradley Iott, $M P H^{2,3}$

Denise Anthony, $P b D^{2}$

Jodyn Platt, $\mathrm{PbD}^{4}$

'Department of Kinesiology and Community Health, University of Illinois at Urbana-Champaign, Champaign, Illinois

${ }^{2}$ Department of Health Management and Policy, University of Michigan School of Public Health, Ann Arbor, Michigan

${ }^{3}$ School of Information, University of Michigan, Ann Arbor, Michigan

${ }^{4}$ Department of Learning Health Sciences, University of Michigan Medical School, Ann Arbor, Michigan

sin

MORE ONLINE

www.annfammed.org
Conflicts of interest: authors report none.

\section{CORRESPONDING AUTHOR}

Minakshi Raj

2007 Huff Hall

1206 South Fourth Street

Champaign, IL 61820

mraj@illinois.edu

\begin{abstract}
Telehealth can benefit older adults during COVID-19. The purpose of this study was to understand benefits and barriers to telemedicine visits for older adults from the perspectives of family caregivers. A cross-sectional, online survey was conducted across the state of Michigan with family caregivers $(n=90)$ who responded to open- and closed-ended questions. Perceived benefits of telemedicine included access and rapport; barriers included the appropriateness of telemedicine for certain health care needs. Telemedicine is a likely to remain beyond COVID-19 and can facilitate access to and continuity of care. There are barriers, however, that must be addressed, especially among older patients.
\end{abstract}

Ann Fam Med 2022;20:69-71. https://doi.org/10.1370/afm.2760.

\section{INTRODUCTION}

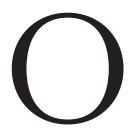
ne of the major shifts in health care delivery during the COVID-19 pandemic has been the rapid implementation of telehealth (hereon, specifically audio/video mediated synchronous health care visits) to improve patients' access to health care services while limiting risk of exposure to COVID19 in health care settings. ${ }^{1,2}$ Older adults stand to benefit tremendously from telehealth as they are more likely to have multiple chronic conditions requiring multiple health care encounters with different types of providers; yet, they are less likely to use telehealth because of barriers such as digital literacy and privacy concerns. ${ }^{3,4}$ Some older adults receive assistance with telehealth from family caregivers. ${ }^{5}$ In the current study, we conducted a survey with family caregivers residing in Michigan to learn about their older relative's experiences with telehealth visits and caregivers' participation and perceived benefits and challenges with those visits. ${ }^{6}$

\section{METHODS}

We recruited adult family caregivers using the University of Michigan Institute for Clinical and Health Research's online research platform between May 1 and June 30, 2020. ${ }^{7}$ We provided a broad, inclusive definition of "family caregivers" and prompted participants to message the study team with any questions about their eligibility (being an unpaid family caregiver of a relative aged $\geq 60$ years residing in Michigan). Of 126 participants who opted into the study, 90 met our eligibility criteria and completed a 10-minute Qualtrics survey which included closed-and open-ended questions. Survey questions were adapted from previous surveys and developed by the study team ${ }^{8}$ (Supplemental Appendix).

We summarized information about participants' relative's use of telehealth (eg, number of visits, if any, purpose of visit) and caregivers' participation in those visits. Open-ended questions were related to (1) concerns about using telehealth to communicate with their relative's health care provider and (2) general comments about experiences or thoughts about telehealth during COVID-19 (Supplemental Appendix). We provided participants with a standard definition of telehealth. ${ }^{9,10} \mathrm{We}$ conducted an inductive thematic analysis of responses to these open-ended questions. The study team created an initial codebook, then iteratively reviewed and refined the codebook and coded all responses. The study was given permission with exemption from the (blinded) Institutional Review Board. Participants provided written consent. 


\section{RESULTS}

A total of 90 family caregivers completed the survey. The average age was 53.1 years. A majority identified with being a woman $(n=78)$ and White, non-Hispanic $(n=82)$. Over one-half of $(n=48)$ reported being in very good to excellent health before COVID-19; fewer $(n=40)$ reported being in very good to excellent health during COVID-19. Almost onehalf of the caregivers $(n=41)$ reported that their older relative had undergone a telehealth visit via telephone or video during the study period with a general doctor $(n=18)$, a specialist doctor $(\mathrm{n}=17)$, or another provider (eg, nurse practitioner, mental health, or other provider $[n=6]$ ) either for a new or ongoing health condition, prescription renewal, wellness visit, or end-of-life consultation. About one-third of caregivers reside in the same household as their relative $(n=34)$. Most caregivers support relatives with chronic condition(s) (eg, cancer, heart disease) $(\mathrm{n}=59)$, orthopedic/musculoskeletal issues $(n=46)$, or memory loss $(n=40)$. Over one-half of caregivers $(n=46)$ support a relative age $\geq 80$ years.

Nearly one-quarter of participants $(n=20)$ described benefits of telehealth in open-ended comments about their perspectives on telehealth including those whose relative had a telehealth visit $(\mathrm{n}=13)$ and those whose relative had not $(n=7)$ (Table 1$)$. Perceived benefits included increasing access to care, continuity of care, limiting risk of exposure to COVID-19, and improving the relationship and rapport between their older relatives and care providers. More participants $(n=29)$, some of whom also reported benefits, described concerns about their older relative's ability to access and use the technology independently, relevance of telehealth for addressing their relatives' specific needs and concerns, and patient-clinician rapport. For example, some participants were skeptical of the efficacy of the approach in helping their relatives with chronic conditions requiring special types of medical technologies, a doctor's touch, hands-on assessments (eg, muscle strength) or close visual observation. Another concern was that their relative's worries would be dismissed via telehealth, and/or that their relative would be less forthcoming and honest about their concerns via telehealth.

Of those caregivers with a relative who had a telehealth visit $(n=41)$, less than one-half $(n=16)$ participated from the same location as their older relative (ie, part of the same audio/video connection) and most $(n=10)$ live in the same household as their older relative. Caregivers saw their

\section{Table 1. Family Caregivers' Perceived Benefits and Barriers of Telehealth}

\begin{tabular}{|c|c|}
\hline Theme & Representative Quote \\
\hline \multicolumn{2}{|l|}{ Benefits } \\
\hline \multirow[t]{3}{*}{ Access to care } & $\begin{array}{l}\text { It's been a good experience and saved us worry about potential exposure to COVID in a medical setting... We had visits with several } \\
\text { providers - gastroenterology, neurology, physical medicine, orthotics, speech therapy. Each provider adapted their evaluation to the } \\
\text { televisit medium. }\end{array}$ \\
\hline & I am very glad it's offered. Dad can't get into a car easily, and we worry about exposure to COVID-19. \\
\hline & $\begin{array}{l}\text { Nice to have it available. Just as good as an office visit. But I have equipment to reliably do pulse-ox, temperature and blood pressure } \\
\text { here at home in real time. }\end{array}$ \\
\hline $\begin{array}{l}\text { Relationship } \\
\text { and rapport }\end{array}$ & Meeting online with physicians is comforting and less threatening than going in. \\
\hline \multicolumn{2}{|l|}{ Barriers } \\
\hline \multirow[t]{2}{*}{$\begin{array}{l}\text { Older adults' } \\
\text { access to and } \\
\text { comfort with } \\
\text { technology }\end{array}$} & $\begin{array}{l}\text { My mother in law has a limited set of technology skills (email, browsing social media) and when she needs to step outside those skills } \\
\text { she becomes very anxious. She does manage to figure it out-she has learned Zoom for instance-but one of our biggest chal- } \\
\text { lenges as caregivers is helping her manage her stress and anxiety around technology. I think most people, regardless of age, get } \\
\text { really frustrated when their tech isn't working like they want it to, but it seems even harder for her and the other elders I care for... } \\
\text { While telemedicine could work for her (she hasn't used it yet, to my knowledge), it will probably not be something she initiates, } \\
\text { and would also be something she wants hands-on help with. When she's staying with me, she can get that, but when she's at her } \\
\text { home I think she could struggle. }\end{array}$ \\
\hline & My relative is unable to navigate technology such as 3-way call nor able to accurately convey what was talked about in her phone visit. \\
\hline \multirow{2}{*}{$\begin{array}{l}\text { Appropriateness } \\
\text { of telehealth } \\
\text { for concerns }\end{array}$} & $\begin{array}{l}\text { I believe in order to have a meaningful visit with the elderly you need to be present. Watching their mobility, their body language, } \\
\text { and non-verbal communications is more important than words often. On video so much is missed. }\end{array}$ \\
\hline & $\begin{array}{l}\text { One of several reasons she sees a doctor is to have an infected skin wound examined that is on her back. My mom is uncomfort- } \\
\text { able even using a computer... It is also impossible for her due to bone issues and arthritis to hold up an electronic device in the } \\
\text { precise position with adequate lighting for a doctor to be able to give an opinion on her healing. I have taken pictures before } \\
\text { and sent them to the doctor but it is still not a full substitute for a visit, nor something she could have done without my help. }\end{array}$ \\
\hline \multirow[t]{2}{*}{$\begin{array}{l}\text { Patient-provider } \\
\text { rapport }\end{array}$} & $\begin{array}{l}\text { I worry about them using telemedicine to replace face to face doctor visits. They are hard of hearing, they get upset and frus- } \\
\text { trated easily, they are intimidated by technology. They also try to put on a good face and make it seem like everything is okay... } \\
\text { It is easier to hide problems via computer than in person. }\end{array}$ \\
\hline & $\begin{array}{l}\text { He isn't forthcoming about all of his symptoms and downplays what he is experiencing. I worry if the doctor can't see him in per- } \\
\text { son, she won't get the full picture. }\end{array}$ \\
\hline
\end{tabular}

Note: Source is authors' analysis of data. 
Table 2. Family Caregivers' Experiences With Participating in Telehealth Visits and Perceived Benefits and Barriers of Telehealth

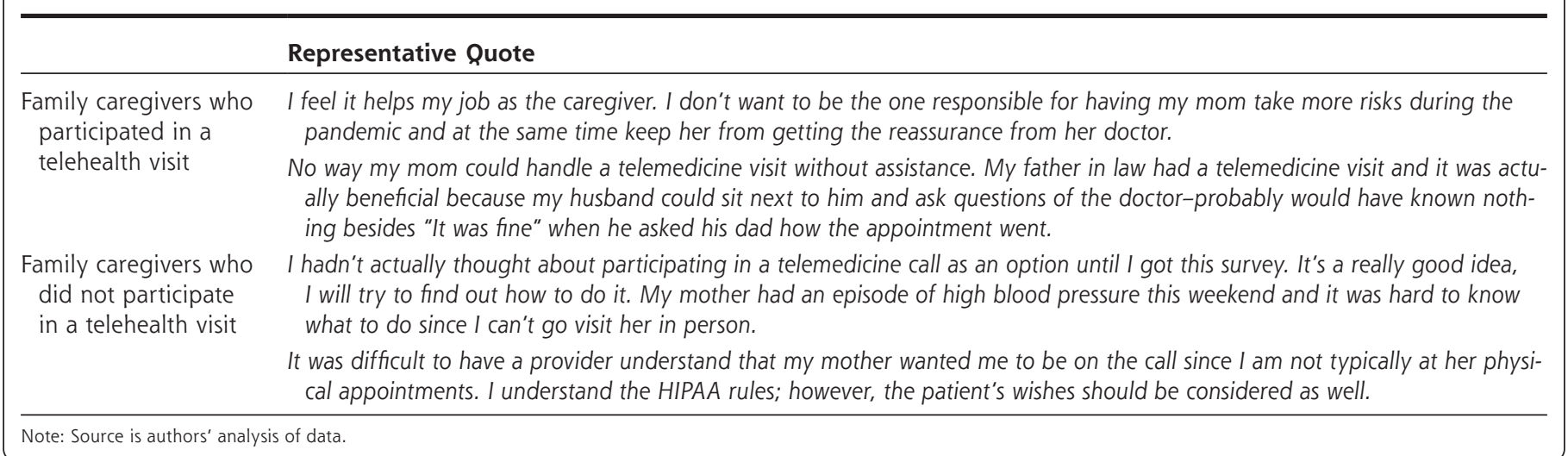

inclusion as being critical to ensuring that questions and concerns were addressed even if their older relatives were not forthcoming on their own (Table 2).

\section{DISCUSSION}

Family caregivers of older adults perceive several benefits and barriers to using telehealth for health care visits. Telehealth is likely to persist beyond COVID-19 given its demonstrated effectiveness in increasing access and continuity of care. ${ }^{1} \mathrm{Cli}$ nicians should discuss benefits and limitations of teleheath with older patients and their caregivers, so patients are empowered to decide between in-person or virtual care. Policies to include family caregivers in telehealth visits may be critical for facilitating their older adult's access to health care via telehealth, and therefore, older adults' ability to age in place. In the absence of a co-located caregiver, clinicians should also work with patients and social workers to identify trusted individuals who can provide technical support and advocacy. Despite limits to generalizability, this rapid assessment during COVID19 provides initial findings that can be used for future studies examining family caregivers' perceptions and experiences with their older relative's telehealth visits.

\section{Read or post commentaries in response to this article.}

Key words: COVID-19; caregivers; telemedicine; aging

Submitted December 2, 2020; submitted, revised, April 19, 2021; accepted July 12, 2021.

Acknowledgments: We thank the family caregivers who took the time to share their experiences and concerns with us.

\section{References}

1. Hollander JE, Carr BG. Virtually perfect? Telemedicine for Covid-19. N Engl J Med. 2020;382(18):1679-1681. 10.1056/NEJMp2003539

2. LaRosa J. The benefits of telehealth during a pandemic-and beyond. The Commonwealth Fund. Published 2020. Accessed Jul 3, 2020. https://www. commonwealthfund.org/blog/2020/benefits-telehealth-during-pandemicand-beyond

3. Steinman MA, Perry L, Perissinotto CM. Meeting the care needs of older adults isolated at home during the COVID-19 pandemic. JAMA Intern Med. 2020;180(6):819-820. 10.1001/jamainternmed.2020.1661

4. Anthony DL, Campos-Castillo C, Lim PS. Who isn't using patient portals and why? Evidence and implications from a national sample of US adults. Health Aff (Millwood). 2018;37(12):1948-1954. 10.1377/hlthaff.2018.05117

5. Chen J, Malani P, Kullgren JT. Patient portals: improving the health of older adults by increasing use and access. Health Affairs blog. Sep 6, 2018. https:// www.healthaffairs.org/do/10.1377/hblog20180830.888175/full/

6. MDHHS. Family caregiving. Aging and Adult Services Agency. Published 2020. Accessed Aug 11, 2020. https://www.michigan.gov/osa/0,4635,7-234-473342--,00.html

7. MICHR. Leveraging UMHealthResearch.org to onnect COVID-19 study participants with research teams. Michigan Institute for Clinical and Health Research. Published Apr 30, 2020. Accessed Jul 3, 2020. https://michr. umich.edu/news/2020/4/30/leveraging-umhealthresearchorg-to-connectcovid-19-study-participants-with-research-teams

8. HINTS. Health Information National Trends Survey. National Cancer Institute. Published 2020. Accessed May 21, 2020. https://hints.cancer.gov

9. Telemedicine and telehealth. Office of the National Coordinator for Health Information Technology (ONC). Published 2020. Accessed Oct 19, 2020. https://www.healthit.gov/topic/health-it-health-care-settings/ telemedicine-and-telehealth

10. Mayo Clinic staff. Telehealth: technology meets health care. Mayo Clinic: Healthy Lifestyle; Consumer Health. Published May 15, 2020. https:/l www.mayoclinic.org/healthy-lifestyle/consumer-health/in-depth/telehealth/ art-20044878

\section{Supplemental materials}

